\title{
Highlights from the 11th Annual Scientific Meeting of the International Society for Minimally Invasive Cardiothoracic Surgery
}

\author{
Lawrence S. Lee, MD, and Jonathan Daniel, MD
}

The 2008 Annual Scientific Meeting of the International Society for Minimally Invasive Cardiothoracic Surgery was held in Boston from June 11 to June 14. Over the course of the meeting, participants and attendees learned about the latest advances and the state of the art in minimally invasive techniques and technologies for cardiothoracic surgery. This review provides a brief overview of some of the innovative topics that garnered significant discussion during the scientific sessions.

\section{CARDIAC SURGERY}

\section{Surgical Treatment of Atrial Fibrillation}

Atrial fibrillation remains a significant problem in the cardiothoracic patient population and a truly effective, definitive treatment remains elusive. Innovative developments presented at the meeting focused on minimally invasive access approaches, such as minithoracotomy, robotic, totally endoscopic, and closed chest techniques, to perform atrial ablation surgery. Traditional approaches for procedures such as the Cox-Maze have required a full median sternotomy and cardiopulmonary bypass. New techniques have allowed the Cox-Maze procedure to be performed successfully in 16 patients via a right minithoracotomy and femoral vessel cannulation, ${ }^{1}$ as well as a totally pericardioscopic ex-Maze procedure completed in 22 patients without cardiopulmonary bypass and excellent short-term results. ${ }^{2}$ Other topics of discussion included the extent of lesion sets and the optimal choice of an energy source. The consensus seemed to be that lone pulmonary vein isolation is insufficient for successful control of atrial fibrillation, and that the use of biatrial lesion sets or the Cox-Maze procedure is generally the most successful. Bipolar radiofrequency ablation in combination with cryothermia seemed to provide the most consistent results, although there was some debate about the need for exclusion of the left atrial appendage.

\section{Percutaneous Valvular Therapies}

There has been tremendous attention and excitement in recent years within the cardiovascular community surrounding percutaneous valve therapies, with initial studies and devices focused on the aortic valve. The first clinical experience in

\footnotetext{
From the Brigham and Women's Hospital, Harvard Medical School, Boston, Massachusetts.

Received for publication July 31, 2008; accepted for publication July 31, 2008.

Address for reprints: Lawrence S. Lee, MD, Division of Cardiac Surgery, Brigham and

Women's Hospital, Harvard Medical School, Boston, Massachusetts (E-mail:

LLee12@partners.org).

J Thorac Cardiovasc Surg 2008;136:1107-9

$0022-5223 / \$ 34.00$

Copyright $(c) 2008$ by The American Association for Thoracic Surgery

doi:10.1016/j.jtcvs.2008.08.003
}

the United Kingdom of percutaneous aortic valve replacement via the femoral route in 27 patients was presented. ${ }^{3}$ All patients were high risk for conventional surgery with severe symptomatic aortic stenosis, and the third-generation CoreValve aortic revalving system (CoreValve Inc, Irvine, Calif.) was deployed. The mean aortic valve gradient decreased from $44 \mathrm{~mm} \mathrm{Hg}$ to $8 \mathrm{~mm} \mathrm{Hg}$, whereas the aortic valve area increased from $0.75 \mathrm{~cm}^{2}$ to $1.5 \mathrm{~cm}^{2}$ with $4 \%$ mortality at 30 days. This was accompanied by a significant improvement in New York Heart Association status in the early postprocedure period, suggesting that percutaneous aortic valve replacement is a safe and effective treatment for severe aortic stenosis in high-risk and elderly patients.

Transapical aortic valve implantation is another approach for percutaneous aortic valve therapy. Ninety-four high-risk, elderly patients were treated with the Edwards SAPIEN device (Edwards Lifesciences, Irvine, Calif) in a hybrid operation under fluoroscopic and echocardiographic guidance. The majority of cases were completed without bypass, and the 30-day and 1 -year survivals were $90 \%$ and $71 \%$, respectively. Additional larger-scale studies are needed to fully assess the clinical impact of these percutaneous devices, but early data show that they may be of benefit in the highrisk patient population.

\section{Coronary Revascularization}

Sutureless anastomotic devices for coronary revascularization is a burgeoning field of interest and the topic of significant amounts of research. These devices may be particularly relevant and useful in allowing minimally invasive approaches for coronary surgery, such as totally endoscopic beating heart procedures.

The first report of the Food and Drug Administration trial assessing the efficacy of the Pas-Port (Cardica, Inc., Redwood City, Calif) sutureless anastomosis device for coronary revascularization was presented. More than 200 patients were included in the multicenter prospective study, and initial results showed that the Pas-Port device was not inferior to hand-sewn anastomoses. The device had graft patency similar to the hand-sewn technique but did offer a marginal time savings of just more than 5 minutes per surgery. There was no increase in adverse events associated with use of the Pas-Port device. The safety of the Heartstring device (MAQUET, Rastatt, Germany) in the construction of clampless proximal coronary anastomoses was assessed in 434 patients undergoing isolated coronary artery bypass grafting. The results showed that the anastomoses can be successfully created with minimal stroke risk even in patients with severe ascending aortic atherosclerosis. ${ }^{4}$ 


\section{Abbreviation and Acronym \\ VATS $=$ video-assisted thoracic surgery}

\section{Minimally Invasive Valve Approaches and Techniques}

Minimally invasive mitral valve surgery is quickly becoming the standard of care in many institutions. The approach used most commonly is a right minithoracotomy, often via port access. Such techniques may be particularly useful in reoperative cases, in which median sternotomy can be technically challenging because of limited exposure and previous bypass grafts.

A dual-center review of 890 video-assisted minimally invasive mitral valve surgeries, including repair or replacement, showed that such procedures alone or in combination with other cardiac procedures are safe and reproducible. ${ }^{5}$ Thirty-day mortality for all cases was $3 \%$, with the most common complication being reexploration for bleeding. Myocardial protection was achieved via antegrade cardioplegia and transthoracic clamping, cold fibrillatory arrest, or endoaortic balloon occlusion. The latter was associated with a statistically insignificant higher incidence of aortic dissection.

Minimally invasive reoperative mitral valve surgery in 151 patients via right lateral minithoracotomy and femoral cannulation for cardiopulmonary bypass revealed 3-year survivals of $80 \%$ and $73 \%$ for valve repair and replacement, respectively. ${ }^{6}$ Early mortality was $5 \%$, which was significantly lower than the predicted EuroSCORE mortality risk of $17 \%$, demonstrating that minimally invasive mitral valve reoperation via this approach is safe and effective with good medium-term results. A second study of 651 cases of port-access reoperative mitral valve surgery via a right minithoracotomy showed similar excellent results, with only 1 conversion to sternotomy for acute aortic dissection. $^{7}$

\section{THORACIC SURGERY}

\section{Minimally Invasive Thoracic Surgery}

The thoracic sessions provided a forum for discussion of the continued evolution of thoracoscopic, robotic, and hybrid procedures for the entire gamut of thoracic surgery. The conference format encouraged active participation of the attendees in a practical arrangement that allowed for direct interaction and instruction from an assembly of the leading international experts in minimally invasive surgery. The thoracic postgraduate course reviewed new techniques in mediastinal staging- video-assisted thoracic surgery (VATS) procedures, including sleeve resection and sympathectomy; endoluminal therapies; radiofrequency ablation; and setup for robotic procedures.

\section{Mediastinum and Staging}

Controversy exists regarding the completeness of resection for VATS approaches to thymectomy and the use of less-invasive techniques when thymoma is involved. A review of 72 patients who underwent VATS thymectomy with a right-sided approach demonstrated complete stable remission rates that were comparable $(41.2 \%$ for nonthymoma vs $38 \%$ for thymoma) and similar to previous reports via open techniques. ${ }^{8}$

Surgical staging of the mediastinum in non-small cell lung cancer has always played an important role in determining operative candidates. Traditional cervical mediastinoscopy has been limited by higher false-negative rates because of nodal sampling and inability to assess lymph nodes in additional stations, such as levels 5 and 6 (for evaluation of left upper lobe tumors). The combination of endoscopic techniques and extended transcervical approaches is allowing surgeons to overcome these limitations. There is an initial learning curve to the use of transcervical mediastinotomy for anteroposterior window evaluation. A review of 100 patients who underwent the technique found that careful review of preoperative computed tomography scan data allows those selecting initial patients for the procedure to increase their probability of successful lymph node dissection. ${ }^{9}$ The product of the thoracic inlet distance and anterior mediastinum was calculated and used to formulate a cervical mediastinotomy index that accurately predicted difficult patient populations for this technique.

The largest reported series of transcervical extended mediastinal lymphadenectomy for preoperative staging of non-small cell lung cancer was presented. ${ }^{10}$ Operative technique involves a collar incision followed by sternal elevation using a specially developed retractor for full visualization of bilateral recurrent laryngeal nerves and dissection of all mediastinal lymph nodes, with the exception of station 9 . A total of 421 patients were included in the review, and the mean number of dissected nodes in each patient was 38 (range $15-85$ ). N2 nodes were found in $26 \%$ of patients. There was a $2.6 \%$ rate of temporary nerve palsy, and a $0.5 \%$ rate of permanent nerve palsy. Patients who had negative results from transcervical extended mediastinal lymphadenectomy were followed after thoracotomy: Omitted N2 nodes were observed in $4 \%$, and omitted normal mediastinal nodes were observed in $6.8 \%$. This technique of bilateral mediastinal lymphadenectomy yields impressive lymph node dissection rates with a sensitivity of $94.7 \%$ for N2 to N3 node discovery.

\section{Thoracoscopic Advances}

Lung cancer with chest wall invasion has traditionally been recognized as a contraindication to minimally invasive approaches. The first case of en bloc right upper lobectomy with rib resection ${ }^{3-5}$ was performed with 2 ports and a $4-\mathrm{cm}$ 
utility incision. ${ }^{11} \mathrm{~A}$ video of the procedure was presented, and the use of an endoscopic bone cutter was demonstrated, showing that this technique is feasible and may warrant further study for applicability in these patients.

\section{Robotic Surgery}

Several general thoracic procedures have been performed via a totally robotic or robotic-assisted technique. Although laparoscopic or open surgery remains the standard of care, robotic techniques provide several advantages, and additional long-term data may ultimately prove such approaches to be superior in select cases.

Seventy-eight patients underwent a robotic laparoscopic modified Belsey fundoplasty for gastroesophageal reflux disease, a procedure that has traditionally been performed via an open left thoracotomy. ${ }^{12}$ The robotic approach was thought to afford better visualization of the gastroesophageal junction than traditional laparoscopic methods, and when combined with the Belsey wrap it resulted in no evidence of gas bloat syndrome with a mean follow-up of 28 months. The recurrence rate was $5 \%$, and these patients did subsequently require open repair.

Thirty-three patients underwent robotic-assisted right chest esophageal mobilization and lymph node dissection with esophagogastrostomy for esophageal cancer. ${ }^{13}$ The mean operative time was 9 hours with a conversion rate to thoracotomy of $24 \%$ and 1 anastomotic leak (3\%), with no evidence of local recurrence at short-term follow-up. The study demonstrated the feasibility of robotic-assisted esophagectomy, although further refinement of the procedure is required to address the relatively high conversion rate.

A prospective study including 129 patients undergoing robotic-assisted thymectomy via a 3-port left-sided technique demonstrated excellent results that may encourage further centers to adopt this procedure. ${ }^{14}$ The mean operative time was 184 minutes with a $2.3 \%$ conversion rate. The rate of complete stable remission of myasthenia gravis was greater than $40 \%$ with an average follow-up of 16 months. The safety and benefits of traditional VATS approaches to pulmonary lobectomy have been well documented. ${ }^{15}$ In an effort to improve on VATS techniques with better visualization and instrument maneuverability, the robotic system was used in 62 lobectomies with the introduction of a fourth arm. ${ }^{16}$ Setup time averaged 25 minutes with an operative time of 172 minutes. Approximately half of the patients $(45 \%)$ were discharged within 2 days, reinforcing the benefits of less-invasive surgery for anatomic resections.

\section{References}

1. Lee AM, Bailey MS, Aziz A, et al. A minimally invasive full Cox-Maze procedure: technique and results. Presented at: ISMICS Scientific Session 2008. Boston: Mass; June 13, 2008.

2. Kise AC, Wimmer-Greinecker G, Kapelak B, et al. Paracardioscopic ex-maze procedure for atrial fibrillation. Presented at: ISMICS Scientific Session 2008; Boston: Mass; June 13, 2008.

3. Jilaihawi H, Spyt T, Chin D, et al. Percutaneous aortic valve replacement (pAVR) in severe calcific aortic stenosis: first UK experience. Presented at: ISMICS Scientific Session 2008; Boston: Mass; June 12, 2008.

4. Thourani VH, Eldaieef SM, Mutrie C, et al. Outcomes in 434 coronary artery bypass patients using 647 Heartstring ${ }^{\mathrm{TM}}$ devices for the clampless construction of proximal anastomoses. Presented at: ISMICS Scientific Session 2008; Boston: Mass; June 12, 2008.

5. Modi P, Rodriguez E, Gersch KA, et al. Two institution experience with 890 video-assisted minimally invasive mitral valve surgeries. Presented at: ISMICS Scientific Session 2008; Boston: Mass; June 12, 2008.

6. Seeburger J, Falk V, Kuntze T, et al. Redo mitral valve surgery via right sided mini-thoracotomy is safe and effective. Presented at: ISMICS Scientific Session 2008; Boston: Mass; June 12, 2008

7. Meyer SR, Szeto WY, Augoustides JG, et al. Reoperative mitral valve surgery using the port-access right mini-thoracotomy approach. Presented at: ISMICS Scientific Session 2008; Boston: Mass; June 12, 2008.

8. Keating CP, Kong Y, Tay V, et al. VATS thymectomy for myasthenia gravis via a right-sided approach: long term follow up. Presented at: ISMICS Scientific Session 2008; Boston: Mass; June 12, 2008.

9. Cameron R, Andaz S, Peng R, et al. Transcervical mediastinotomy access to the AP window: patient selection and results. Presented at: ISMICS Scientific Session 2008; Boston: Mass; June 12, 2008.

10. Zieliski M, Kudzai J, Hauer L, et al. Transcervical extended mediastinal lymphadenectomy (TEMLA): results of staging in 421 patients with NSCLC. Presented at: ISMICS Scientific Session 2008; Boston: Mass; June 12, 2008.

11. Nwogu C, Yendamuri S, Demmy T. Thoracoscopic lobectomy with chest wall resection. Presented at: ISMICS Scientific Session 2008; Boston: Mass; June $12,2008$.

12. Gharagozloo F, Margolis M, Tempesta B. Robotic laparoscopic Belsey fundoplasty for gastroesophageal reflux disease. Presented at: ISMICS Scientific Session 2008; Boston: Mass; June 12, 2008.

13. Gharagozloo F, Margolis M, Tempesta B, et al. Robotic assisted abdomen/right chest (Ivor Lewis) esophagectomy for esophageal cancer. Presented at: ISMICS Scientific Session 2008; Boston: Mass; June 12, 2008.

14. Ruckert JC, Swierzy M, Ismail M, et al. Robotic assisted thymectomy: a 5 year experience. Presented at: ISMICS Scientific Session 2008; Boston: Mass; June $12,2008$.

15. Onaitis MW, Peterson RP, Balderson SS, et al. Thoracoscopic lobectomy is a safe and versatile procedure: experience with 500 consecutive patients. Ann Surg. 2006;244:420-5.

16. Lee KA. Enhancement of minimal invasive thoracic surgery: four arm robotic assisted pulmonary lobectomy. Presented at: ISMICS Scientific Session 2008; Boston: Mass; June 13, 2008 